\title{
The Phonology-Morphology Interface from the perspective of infixation
}

\author{
Alan C. L. Yu
}

\section{Introduction}

The nature of the interaction between phonology and morphology has gained renewed interests in the phonological literature in recent years. ${ }^{1}$ The advent of Optimality Theory (OT) in particular has driven many researchers to rethink earlier assumptions about the nature of the PhonologyMorphology interface. For example, the rejection of serialism and the strict adherence to only two levels of representations have prompted new investigations on opacity and the need for intermediate representations (e.g., Hermans and van Oostendorp 1999; McCarthy 1999); OT's emphasis on output wellformedness raises questions on the need for underlying representations itself (e.g., Burzio 2005; Flemming 1995). This paper focuses on one such area of debate, namely, the extent of influence the phonological component may exert on morphology. Within traditional OT, phonological constraints interact with morphological ones directly. The integration of constraints grants phonology a much stronger hand over morpheme realization than any previous theories have assumed. The most drastic consequence of this integration can be observed in the area of affix placement. In particular, phonological considerations may determine the linear position of an affix relative to a stem, often time in direct conflict with the underlying subcategorization restriction of the affix. Infixation is hailed as the prime example of such a heavy-handed interaction. The linear position of an infix with respect to the domain of affixation is seen as a complex interaction between the shape of the infix and the general phonotactics of the language. For example, while the actor focus marker, -um-, in Tagalog (Austonesian, Meso-Philippine) is assumed to be underlyingly a prefix, it is realized as an infix (e.g., sulat 'to write' $\sim$ s-um-ulat $/ * u m$-sulat) due to constraints against coda consonants (McCarthy and Prince 1993a) or onsetless syllables (Orgun and Sprouse 1999).

This paper argues that this kind of encroachment of the phonological component into the domain of affix placement is neither necessary nor 
sufficient to account for the phenomenon it proposes to explain. In particular, typological evidence reveals no empirical support for such a movement-based analysis of infixation. The distribution of infixes within the domain of affixation is better explained by their diachronic origins. This issue gains renewed urgency in the context of current debate concerning the division of labour between diachronic and synchronic explanations. Many current theories of infixation, and of grammar in general, assume that, all else being equal, naturalness and universal typological tendencies in phonology and morphology should be captured in the theory of grammar itself in order to attain explanatory adequacy. From this point of view, the theory of grammar not only should "account" for what is found in language, but also "explain" the source of the variations. Such an allencompassing view of grammar is not without detractors, however. Many linguists argue that the sources of naturalness and typological tendencies do not generally reside in the nature of the grammar per se, but are often recoverable only from grammar-external sources, such as diachronic factors or psycholinguistic constraints. The goal of this paper is to provide a bridge between the line of linguistic research that emphasizes the synchronic forces operating in language and research that recognizes the forces of diachrony that help shape them. Synchronists are most often interested in broad generalizations concerning the nature of infix placement based on a small set of languages without paying sufficient attention to the actual placement typology of infixes. On the other hand, the diachronists often ignore the synchronic forces that simultaneously drive and constrain linguistic change. In this paper, I attempt to provide a synthesis and evaluation of these strands of work, placing them in a unified perspective.

This paper is organized as follows. In Section 2, I present a ubiquitous feature of the placement typology of infixes, namely, the Edge-Bias Effect. Section 3 provides arguments against a movement-based model of infixation. A theory of infixation relying on Phonological Subcategorization is presented in Section 4. I argue that the Edge-Bias Effect is the result of historical convergence and language transmission.

\section{Asymmetric distribution of infixes}

Infixes $^{2}$ are often characterized as rare compared to the frequency of other affixes. The presence of infixes in any language implies the presence of suffixes and/or prefixes and there are no languages that employ infixation exclusively (Greenberg 1966: 92). Infixes are not at all difficult to find, 
however. English-speaking readers will no doubt recognize examples of the expletive infix (e.g., fan-fuckin-tástic and Tatam-fuckin-gouchee; McCarthy 1982), the ma-infix (e.g., saxo-ma-phone and edu-ma-cate; Yu 2004), or even the Hip-hop iz-infix (e.g., h-iz-ouse or b-iz-itch; Viau personal communication). Despite their relative rarity, infixes are found in a diverse set of locations within words and morphological formatives. The range of infixation patterns in English already illustrates this point. While the expletive, when used infixally, appears before the stressed syllable, the $m a$-infix prefers to come after a trochaic foot. The -iz-infix popularized by Hip-Hop singers is attracted by stress as well. However, it differs from the first two patterns by lodging itself before the stressed vowel.

This apparent richness and diversity, however, mask a striking feature of infixes, namely, the asymmetric typology of their placement properties. It has long been recognized that the placement of infixes converges to two locales, despite its diversity in shape and function. A survey of 154 infixation patterns from more than 100 languages revealed that infixes invariably appear near one of the edges of a stem or next to a stressed unit ( $\mathrm{Yu}$ 2003). ${ }^{3} 137$ of these infixes (i.e. 89\%) are edge-oriented (Table 1). That is, infixes predominately (Fisher Exact test $p<0.01$ ) lodge themselves close to one of the edges of the domain of infixation, which may be a root, a stem (i.e. root or root plus some affixes) or a free-standing word (cf. Moravcsik 2000; Ultan 1975). I refer to this asymmetric distribution of infixes as the Edge-Bias Effect.

Table 1. Distribution of edge-oriented and prominence-driven infixes

\begin{tabular}{lrrrr}
\hline & Fixed Segment & Reduplication & \multicolumn{2}{c}{ Total } \\
\hline Edge-oriented & 94 & 43 & 138 \\
Prominence-driven & 6 & 11 & 17 \\
Total & & & 154 \\
\hline
\end{tabular}

What accounts for this distributional skewing? Over the years many theories have been developed to deal with the placement properties of infixes. Broadly speaking, there are two main traditions. One approach, Phonological Subcategorization, embraces the morpho-phonological mismatching nature of infixes by treating them as affixes that subcategorize for a phonological element, rather than a morphological one (e.g., Inkelas 1990; Kiparsky 1986; McCarthy and Prince 1986; Broselow and McCarthy 1983/1984). Others have argued that infixes are "defective" adfixes (i.e. prefixes and suffixes), and that their underlying prefixing or suffixing na- 
ture is obscured by synchronically motivated (morpho-)phonological factors (e.g., Prince and Smolensky 1993; Moravcsik 1977; McCarthy and Prince 1993ab; Halle 2001). Let us call this movement-based view of infixation Phonological Readjustment.

This paper advocates the superiority of Phonological Subcategorization over Phonological Readjustment. In particular, I argue that Phonological Subcategorization, when embedded within a proper model of the interaction between synchronic and diachronic factors, offers a comprehensive explanation of the placement properties of infixes. Before going into detail my approach to infixation, I first articulate why Phonological Readjustment is not adequate for the task.

\section{Against Phonological Readjustment}

The Phonological Readjustment approach to infixation is deficient in many respects. To begin with, it is applicable to edge-oriented infixes only; prominence-driven infixes are accounted for in terms of Prosodic Subcategorization, a subtype of Phonological Subcategorization (cf. McCarthy and Prince 1993ab). The main weakness of Phonological Readjustment is more fundamental, however. A central argument for a Phonological Readjustment model of infixation rests on the premise that the infixability of an affix is partly determined by the phonological composition of the affix itself and the context in which it appears (cf. Anderson 1972; Cohn 1992). Formally, this intuition is captured by the constraint ranking schema, P >> $\mathrm{M}$, one of the three basic tenets of Prosodic Morphology within Optimality Theory (McCarthy and Prince 1993: 110b). This constraint schema embodies the idea that prosody-governed morphology is the result of phonological constraints $(\mathrm{P})$ taking precedence over morphological ones $(\mathrm{M})$. Phonological constraints may be of several varieties (e.g., segmental faithfulness, syllable-well-formedness, segmental markedness etc.); morphological constraints include constraints on faithfulness (e.g., FAITH-Root, FAITH-Affix etc.) and linear precedence (i.e. alignment constraints). It is the latter that are of most relevance in the case of infixation. As alluded earlier, for example, the affix -um- in Tagalog is treated formally as a prefix but is realized as as infix in order to avoid onsetless syllables in the outputs. If infixation were indeed the result of phonological constraints taking precedence over morphological ones, and phonological constraints are constraints penalizing marked structures, it follows that one should never expect to find instances of infixation that yield structures that are prosodi- 
cally less well-formed than their prefixing or suffixing counterparts. Yet, infixes that create prosodically undesirable structures indeed exist. For example, Blevins (1999) reports that in Leti (Austronesian, Central Malayo-Polynesian), nominalizing affixation has eight distinct phonological forms: three infixes $-n i-,-n-,-i-$; the three prefixes $n i-, i-, n i a$; the parafix $i-$ $+-i$ - (i.e. simultaneous prefixation and infixation); and a zero allomorph. Each of these allomorphs has very specific distribution. For example, the infix - $n i$ - appears before the first vowel of the stem when the stem has an initial non-nasal or non-alveolar consonant followed by a non-high vowel (e.g., kaati $\rightarrow$ k-ni-aati 'carving'; pèpna $\rightarrow$ p-ni-èpna 'act of fencing, fence'). When the stem's first syllable contains a high vowel, -ni- realizes as $-n$ - after the initial consonant (e.g., kili $\rightarrow k$-n-ili 'act of looking'; tutu $\rightarrow t$-n-utu 'act of supporting, support'). Another allomorph of $-n i$ - is $-i-$, which surfaces before the first vowel of the stem when the initial consonant is a sonorant or an alveolar consonant (e.g., dèdma $\rightarrow$ d-i-èdma 'act of somoking'; mai $\rightarrow$ m-i-ai 'arrival').

The fact that the nominalizing morph, -ni-, is infixed is puzzling within a prosody-optimizating view of infixation. It is unclear what problems confront the strategy of simply prefixing -ni- to the stem (e.g., *ni-teti instead of $t$-ni-eti 'chop, chopping'). The infixal output contains initial onset clusters and vowel-vowel sequences, both are prosodically undesirable features typologically-speaking. To be sure, infixation in Leti is not motivated by edge-avoidance. That is, it will not suffice to assert that the coincidence of the left edges of the root and the output prosodic word trumps the prefixing requirement of the nominalizing affix since the nominalizer prefixes to vowel-initial stems directly (e.g., $n$-osri $\rightarrow \boldsymbol{i}$-osri, $\boldsymbol{n i}$-osri 'act of hunting'; $n$-atu $\rightarrow \boldsymbol{i}$-atu, ni-atu 'knowledge'). ${ }^{4}$

What the Leti case illustrates is the fact that infixation can occur for no obvious prosodic or phonotactic gains. Prosodic optimization offers us no insight as to why such infixation patterns exist at all. One may appeal to edge-avoidance to account for certain cases, but such an analysis would have lost the appeal of the Phonological Readjustment approach, that is, the functional motivation for an affix to migrate to minimize output markedness. The list of non-functionally motivated infixes may be expanded to include the myriad cases of infixes that neither improve nor worsen the markedness of the output. For example, in Hua (Trans-New Guinea, Eastern Highlands), the negative marker - ?a- appears before the final syllable (e.g., zgavo $\rightarrow$ zga ?avo 'not embrace'; harupo $\rightarrow$ haru ?apo 'not slip; Haiman 1980). The prefixal or suffixal counterpart of such a CV marker would have resulted in prosodically equally well-formed outputs. No obvious 
functional motivations can be adduced for the infixing of such a morpheme.

The purported functional bond between the shape of an infix and its position with respect to the host is further weakened upon a closer examination at the typology of infix shape and its placement property. Of the forty cases of fixed segment VC infixation surveyed, twenty-three are from Austronesian languages, eleven from Austro-Asiatic languages, while only six are from other languages. Of the thirty-four VC infixes that come after the first consonant or before the first vowel of the stem, all but one comes from the Austronesian and the Austro-Asiatic families. The fact that the majority of the post-onset VC infixes belong to one of two language families suggests that such cases might be features inherited from their respective proto-languages. In contrast, about $20 \%$ of the fixed-segment infixes surveyed are CV in shape, about $10 \%$ are just a single vowel, and about $44 \%$ are monoconsonantal. Of these coda- or cluster-generating monoconsonantal infixes, only five are from Austronesian and three from Austro-Asiatic. Thus, a closer look at the cross-linguistic evidence offers no concrete evidence for an ethological understanding of infixation at the synchronic level; the position of an infix is not a function of its immediate environment. The purported functional connection may simply reflect a bias introduced by impoverished sampling in previous studies. Since the constraintbased approach to Phonological Readjustment was built upon this ethological assumption of infix placement, the refutation of this premise calls for an alternative understanding of the phenomenon. How then should the asymmetric distribution of infixes be understood? The remainder of this paper is devoted to addressing this point.

\section{A comprehensive model of infix distribution}

\subsection{Introduction}

A proper understanding of the placement typology of infixation necessitates an appreciation of the nature of interaction between the diachronic and synchronic forces operating on language. Here, I follow Greenberg (1969) and assume that typological patterns emerge from common diachronic changes in related and unrelated languages. From the point of view of current theories of linguistics, the starting point for discussions of language change is acquisition, that is, the individual's acquisition of a grammar distinct from the one which underlies the output of the preceding gen- 
eration. The key to understanding the "error" in grammar transmission lies in the nature of the input for acquisition. The input data is often wrought with ambiguities. The learner's task is to find a good match between the input and the output of candidate grammars. A model of infix distribution must therefore take into account this dynamic interplay between diachronic and synchronic forces. Such a model must have three main components.

(1) A comprehensive model of infix distribution

a. Grammar-internal constraints:

A theory of phonological subcategorization

b. Grammar-external constraints: constraints on morphological learning constraints on morphological change

c. A theory of interaction between these grammar-internal and grammar-external constraints

First, there must be a formal theory of phonological subcategorization and, by extension, morphological subcategorization that can express the full range of subcategorization relations in language. Allowing affixes to target phonological constituents per se is not sufficient in explaining the restricted typology of infix placement, however. The model must also include a theory of how phonological subcategorization interacts with grammar-external constraints imposed on morphological learning and morphological change. In particular, the theory of affix placement, indeed of grammar as a whole, must be embedded within a temporal axis. As such, the diachronic evolution of infixes is as much an integral part of the explanation as is their treatment within the synchronic grammar. In what follows, I briefly elaborate the nature of each of these components.

\subsection{Infixation as edge misalignment}

The synchronic theory of infix placement adopted in this work is that of Phonological Subcategorization, which inherits the insight of earlier subcategorization-based theories, such as prosodic subcategorization (McCarthy and Prince 1986) and the bi-dependent approach to infixation (Kiparsky 1986; Inkelas 1990), that infixation involves the alignment of a morphological entity with respect to a phonological one. However, it breaks with Prosodic Subcategorization by eliminating the restriction upon which only genuine prosodic categories are allowed to take part in morpho- 
phonological alignment relationship (see also Kiparsky 1986; Inkelas 1990). Subcategorization requirements are stated in the formalism of Generalized Alignment (GA, McCarthy and Prince 1993a: 80). Unlike the traditional formulation of GA, the set of PCat includes units on the CV skeletal tier as well as categories within the Prosodic Hierarchy including the mora.

$$
\begin{aligned}
& \text { Align }\left(\mathrm{Cat}_{1}, \mathrm{Edge}_{1}, \mathrm{Cat}_{2}, \mathrm{Edge}_{2}\right)=_{\text {def }} \\
& \forall \mathrm{Cat}_{1} \exists \mathrm{Cat}_{2} \text { such that Edge }{ }_{1} \text { of } \mathrm{Cat}_{1} \text { and Edge }{ }_{2} \text { of } \mathrm{Cat}_{2} \text { coincide. } \\
& \text { Where } \mathrm{Cat}_{1}, \mathrm{Cat}_{2} \in \text { PCat } \cup \text { GCat } \\
& \text { Edge }_{1}, \text { Edge }_{2} \in\{\text { Right, Left }\}
\end{aligned}
$$

A notion central to the present theory of infix placement is the notion of the pivot, which refers to the morphological and/or phonological unit to which an infix attaches. ${ }^{5}$ So far, I have identified the following set of phonological constituents that may serve as phonological pivots of infixation:

Table 2. Potential pivots of infixation

\begin{tabular}{ll}
\hline Edge pivots & Prominence pivots \\
\hline Leftmost consonant, vowel, or syllable & Stressed vowel, syllable, or foot \\
Rightmost vowel or syllable & \\
\hline
\end{tabular}

Phonological Subcategorization obtains when a designated edge of a morphological constituent $\left(\mathrm{Cat}_{1}\right)$ coincide with a designated edge of a phonological pivot $\left(\mathrm{Cat}_{2}\right)$. For example, in Ulwa (Misumalpan), the construct state (CNS) markers are affixed to the right edge of an iambic foot (e.g., sú:lu $\rightarrow$ sú:-ma-lu 'dog-CNS2'; waráwwwa $\rightarrow$ waráw-kana-wa 'parrot sp.CNS33'; Green 1999: 64). On the present theory, the construct state marker is analyzed as suffixing to an iambic foot. The iambic foot is thus the pivot of the construct state marker.

(3) Ulwa infixal construct noun marker ALIGN ([POSS $]_{\mathrm{Af}}, \mathrm{L}, \mathrm{FT}$ ', R) (McCarthy and Prince 1993a)

'The left edge of the construct noun marker is aligned to the right edge of the head foot.'

The subcategorization frame of an infix is thus formally no different from regular prefixes and suffixes. Infixation obtains, however, when two conditions are satisfied: (i) when the domain of affixation, be it the root, the 
stem or the word, is larger than the size of the phonological constituent, i.e. the pivot, subcategorized by the affix and (ii) when the language tolerates morpheme interruptions. ${ }^{6}$

Now, having asserted that the distribution of infixes is governed by a restricted set of phonological pivots that enter into phonological subcategorization relations with morphological units, one might ask to what extent it is possible to delineate the set of attested phonological pivots without resorting to stipulation. This is the topic of the next section.

\subsection{The Pivot Theory}

The main proposal advanced in this section is the idea that the morphological learning algorithm is biased toward phonological subcategorization relations that are built upon pivots that are perceptually and psycholinguistically salient, where salience may include factors such as ease of recoverability and facilitation in language processing and lexical retrieval. I shall refer to this the Salient Pivot Hypothesis:

Salient Pivot Hypothesis

Phonological pivots must be salient at the psycholinguistic and/or phonetic level.

The idea that certain positions in a word are privileged in the grammar has a long pedigree. As early as Trubetzkoy (1939: 22), it has been recognized that phonological contrasts are sustained to variable degrees depending on the positions of the word. Most relevant to the present discussion is the fact that certain positions in a word are "strong" in that they are either the sole locus licensing a contrast, or that they are more resistant to reduction. For example, Smith (2004) argues that positional augmentation constraints are relativized only to phonologically prominent or "strong" positions, which include the stressed syllable, the released consonants (often the onset of a syllable), the long vowel, the initial syllable, and the morphological root. The final syllable is also the domain of some prominence. Phonologically, certain contrasts are found to be preferentially licensed in final syllables (e.g., tone and vocalic contrasts, Zhang 2001). In acquisition, children are most likely to retain internal-stressed syllables and first and final syllables (Kehoe and Stoel-Gammon 1997). Past research has also shown that the edges of words are psycholinguistically prominent. For example, ShattuckHufnagel (1992) argues that the first consonant of a word is prominent 
based on lexical retrieval evidence. As summarized in Table 3, the set of phonological pivots is a proper subset of the phonologically and psycholinguistically prominent positions.

Table 3. Prominent phonological positions vs. infixal pivots

\begin{tabular}{ll}
\hline $\begin{array}{l}\text { Psycholinguistic salient/ } \\
\text { phonological prominent positions }\end{array}$ & Infixal pivots \\
\hline Initial syllable & First consonant, vowel, or syllable \\
Final syllable & Final consonant, vowel, or syllable \\
Stressed syllable & Stressed vowel, syllable, or foot
\end{tabular}

This correlation is significant. The fact that the set of phonological pivots converges with the set of phonologically and psycholinguistically prominent positions suggests that the Salient Pivot Hypothesis is on the right track. Assuming that a learner is equipped with knowledge of the GA schema, her task is to fill the variable slots with arguments of the correct type based on the available data. The representation of morphological processes, which involves generalizations over the distinction between stems and affixes, emerges as the result of appropriate associations between formatives (Bybee 1995, 2001; Albright 2002; Albright and Hayes 2003).

The Pivot Theory alone does not guarantee the Edge-Bias Effect, however. While the set of phonological pivots may be reduced to two subsets, edge pivots and prominent pivots, there is no inherent bias toward the edge pivots over the prominent pivots. The ultimate source of the Edge-Bias Effect comes from the origins of infixes. In the next section, I show that edge-oriented infixes ultimately originate from adpositional affixes (i.e., prefixes or suffixes). Their peripheral origins give rise to their synchronic edge-oriented profile. Ultimately, it is the preponderance of such infixes with adpositional origin that gives rise to the observed Edge-Bias Effect.

\subsection{The origins of infixation}

Infixes emerge out of ambiguities in morphological parsing. Infixes are predominantly edge-oriented because the set of ambiguity-induced changes that leads to the development of infixation and the mechanism of subcategorization formation during language transmission converge toward outcomes that favor edge-oriented infixes. As foreshadowed above, infixes 
predominately have their origins in historical prefixes and suffixes. Building on the insights of Ultan's (1975) pioneering work on the diachronic typology of infixation, the present typology expands and, along the way, revises the understanding of the diachronic landscape of the origins of infixes. Four sources of infixes are found: morphological entrapment in 4.4.1, phonetic metathesis in 4.4.2, reduplication mutation in 4.4.3, and analogical excrescence in 4.4.4.

\subsubsection{Entrapment}

Entrapment takes place when a morpheme is stranded within a fossilized composite of an outer morpheme and the stem. That is, in a composite $z y X$ where $z$ and $y$ were historical adpositional affixes, when $z$ merges with the root $X$ to form a new root $Z X$ such that the relative independent existence of $z$ or $X$ is no longer recoverable synchronically, $y$ is said to be entrapped in a form like $Z \boldsymbol{y} X$ (similar logic applies to entrapped suffixes). Entrapment is the most often invoked mechanism of infixation. A prime example comes from the languages of the Muskogean family. (The following discussion draws heavily on work by Haas 1977 and Martin and Munro 2005.)

Many morphemes, most notably the agreement markers, in the Muskogean languages are infixes. However, the locations of these infixes are remarkably consistent. Haas (1977) was first to argue that the similarity between the placements of the disparate array of morphological entities can be explained as the result of the merger of a verb plus auxiliary verb complex in the history of the languages. Historical prefixes on the auxiliary verb are, therefore, "trapped" between the main verb and the historically separate auxiliary (i.e. VerbStem Affix-Auxiliary). For example, the ProtoMuskogean (PM) plural affix, *oho-, developed into a pre-final syllable infix, -ho-, in Creek-Seminole and Hitchiti-Mikasuki (e.g., Mikasuki: hica 'see'/ ci-hi.ho:ca-la:ka 'he will see you all'; impa- 'eat'/ imhopa- 'eat $\left.(\mathrm{PL})^{\prime}\right)$. This and other inflectional infixes target the final syllable because the ertswhile auxiliary verbs, to which historically the inflectional affixes prefixed, were monosyllabic in PM. Similarly, in PM, the mediopassive proclitic *il- appears after the applicative *a- (PM: *a-il-pica 'be looked at') and the plural *oho- (PM: *oho-il-icca 'be shot'). In the Southern Muskogean languages, however, it appears as an infix (e.g., Alabama: o.ti 'make a fire' $\rightarrow$ ollt 'kindling'; takco 'rope (v.)' $\rightarrow$ talikco 'be roped'). Martin and Munro (2005) attribute the synchronic distribution of this me- 
diopassive infix to the result of the reanalysis of the prefixes $* a$ - and $*$ oho as part of certain neutral verbs, thus trapping the intervening affix $* i l$. Subsequent analogical extension gives rise to a post-initial vowel distribution of the mediopassive today.

The origins of Muskogean infixes not only exemplify the mechanism of entrapment, but also illustrate an important aspect of the genesis of infixes in general. While the historical plural prefix turned into a pre-final syllable infix due to the monosyllabicity of the grammaticalized auxiliary verbs, the historical mediopassive proclitic gave rise to a post-initial vowel infix. What this shows is that the edge alignment between the infix and the pivot does not always mimic the historical source. The ultimate determinant of what the pivot is rests on the constancy of the potential pivot unit. The fact that the mediopassive infix takes the initial vowel as the pivot rather than the material following it (i.e., the historical root) has to do with the size inconsistency of the historical roots, which may be monosyllabic or disyllabic. Since the set of historical roots do not form a coherent prosodic or phonological unit, it was not adopted as the pivot of mediopassive affixation today. On the other hand, the material preceding the mediopassive can be coherently characterisized as the first vowel since the fossilized prefixes were historically $* a$ - and $* h o(<* o h o)$.

\subsubsection{Metathesis}

Metathesis refers to the transposition between two segments, which can be schematised as AB > BA. Blevins and Garrett $(1998,2005)$ propose that metatheses are the results of sound changes motivated by listener misperception and there are four main types: perceptual, compensatory, coarticulatory, and auditory metatheses. Many infixes are the results of such phonetic metatheses. For example, Benedict (1943) describes that, in Lepcha (Sino-Tibetan, Lepcha), the alternation between intransitive and transitive verbs is marked by the infixing of $-j$ - after the initial consonant (e.g., pok 'cast down' $\rightarrow$ pjok 'cause to cast down'; nom 'smell [intr.]' $\rightarrow$ njom 'smell [tr.]'). He argues that the infix originates from the Tibeto-Burman (TB) causative prefix *s- (e.g., Lepcha nom 'smell (intr.)' corresponds to Tibetan mnam-pa but Lepcha njom 'smell (tr.)' corresponds to Tibetan snam-pa). The palatal glide was originally conditioned by the causative prefix $s$-. After the loss of $*_{s}$ in initial consonant clusters, what used to be coarticulatory palatalization was then interpreted as morphological. This metathesis was not restricted to the intransitive/transitive alternation. Other 
words with $s$-initial consonant clusters also exhibit the epenthesis of the palatal (e.g., TB *s-no 'nose' > Lepcha njo 'snot'; TB *s-nam 'daughterin-law' > Lepcha njom 'daughter-in-law'). An important corollary of the phonetic origin of metathesis is that it restricts the set of metathesisinduced infixes to the set of 'stretch-out' features and segments that are amenable to perceptual confusion (e.g., labial, palatal, pharyngeals, laryngeals, liquid, and rhotic). Moreover, when an adfix metathesizes into an infix, the resultant infix is likely to remain close to one edge of the stem since most cases of phonetic metathesis are local. That is, the transposed segment remains a segment away from its original etymological position. Even if metathesis were long distance, the transposing segment would migrate into relatively prominent positions (i.e., initial or stressed), never into less prominent ones (Blevins and Garrett 2005).

\subsubsection{Reduplication mutation}

Certain infixation patterns, fixed-segmented or otherwise, are descended from historical reduplication constructions. They are the results of reduplication mutation. An example comes from Trukese (Austronesian, Eastern Malayo_Polynesian; the following discussion is based on Garrett 2001). In Trukese, pluractional is marked by $\mathrm{CVC}$ reduplication on consonant initialverbs (e.g., fætæn 'walk' $\rightarrow f æ f-f æ t æ n$ 'be in the habit of walking'; mort 'sit' $\rightarrow \boldsymbol{m} \boldsymbol{m}$-mot 'be sitting'). However, when the verb begins with a vowel or $w$ (the only word-initial glide), the prefix/infix $-V k k$-, where "V" is a copy of the following vowel, is used instead (e.g., is sni 'keep it' $\rightarrow$ ikk-is oni 'be keeping it'; win 'drink' $\rightarrow w$ - $\boldsymbol{k} \boldsymbol{k}$-in 'be in the habit of drinking'). This infix is the result of the loss of word-initial $* k$ in durative verbs with original initial $* k$ (e.g., Pre-Trukic *kakakásu > Trukese okkəss 'treat as a sibling-in-law of the same sex'). The reason for the *kVk-k->*Vkkreanalysis can be most effectively illustrated with the word $\lrcorner s{ }^{\prime}{ }^{W}$ o. $n u$ 'pay chiefly respect to'. Historically, it was *kasam "ónu, its reduplicated form would presumably be *kak-kasam "ómu. After the dropping of the initial $* k$, the reduplicated form became *ak-kasam ${ }^{*} o n u$, which was then reanalyzed as *akk-asam "ónu since *kasam "ónn would have become *asam "ómu. This apparent -Vkk- infix was then generalized to other vowel-initial verbs. A subsequent prevocalic $w$-insertion process affected certain vowel-initial words (e.g., *kóta > wo.t 'coconut husking stick'; *inu $>\boldsymbol{w}$ in 'drink'). $W$-insertion created synchronic base $\sim$ durative alternations of the pattern $w V-\sim w V k k V-$. For example, the reconstructed reduplicated 
form of the word wo.t 'coconut husking stick' would have been *kok-kota. After initial- $k$ dropping, it became *ok-kotta. The $w$-insertion process took place, yielding *wokkotta. Presumably, based on fact that the affix -Vkkwas posited independently of forms like this, *wokkotta would be analyzed as $*_{w}$-okk-otta.

\subsubsection{Analogical excrescence}

Thus far, I have focused on infixes that have historical antecedents. However, this is not always the case. Haspelmath (1995) refers to such instances of morphological creation as morphological excrescence; that is, when an affix emerges in a language without an immediately historical antecedent. A prime example of excrescence is the case of $m a$-infixation found in some varieties of English (e.g., saxo-ma-phone, edu-ma-cate, Ala-ma-bama, onomato-ma-poeia) ${ }^{7}$ This infix is unique for several reasons. First this is a relatively new construction recently introduced into Vernacular American English. It was popularized by the TV animation series, The Simpsons ${ }^{\circledR}$, particularly the speech of the main character, Homer Simpson. This infix is also interesting since it shares no resemblance to any known historical prefix or suffix in the English language. As $m a$-infixation appears to be a colloquialism, it is difficult, if not impossible, to trace the earliest attestation of this construction in the history of English. However, the origin of this affix in not completely lost. The proposal here is that $-m a$ - emerges out of the accidental convergence among two different filler-word constructions in English. That is, when one has a hard time recalling a precise word, name, or phrase, a set of vague, nonsense in English, filler words are often used to fill the gap. I have argued elsewhere that $m a$-infixation emerges out of the accidental resemblance between two particular sets of filler words: the variants of thing and the phrase words based on a question (Yu 2003).
a. Variant of things:
thingamabob, thingmabob, thingamajig, ringamajiggen, ringamajizzer
b. Phrase words based on a question:
Whatdyamecalli, whatchamacallit

As illustrated above, these two sets of filler words/phrases all contain the medial sequence -ma-. The source of this sequence is not recoverable from 
the forms themselves. The listener, upon encountering these sets of words together, drew the conclusion that they are all related by an infix -ma- since these words are all nouns and they share similar pragmatic meaning of casualness and imprecision. The - $m a$ - infix was then extended to other domains to indicate the speaker's casual and noncommittal attitude. It is a small step to extend this usage of -ma- to indicate sarcasm.

What might have further facilitated the creation of the -ma- infix, besides that these words have similar meanings, is the fact that they also share similar prosodic profiles. In both whatchamacallit and thingumabob, for example, the sequence, $m a$, is sandwiched between wo metrical feet, i.e. ('whatcha)ma(,callit) and ('thingu)ma(, bob), which might have been perceived as non-accidental, hence the extraction of a -ma- morpheme. What is crucial here is the fact that the reanalysis is prompted by the inability to recover the placement of $-m a$ - through segmental means. In lieu of that, units at the prosodic level were instead identified as the pivot of affixation (i.e., a disyllabic trochaic pivot).

\section{Conclusion}

Infixation has been heralded as the poster child of the aggressive interaction between phonology and morphology, as conceptualized in OTProsodic Morphology. The typological evidence does not support this view, however. The synchronic typology of infixation reveals no deepseeded connection between the shape of an infix and its surface distribution. The present study contends that the Edge-Bias Effect is the result of two converging forces: an inductive bias in morphological learning that favors salient edge and prominent pivots in subcategorization formation and the preponderance of diachronic pathways that create infixes from adpositional affixes. These two forces are said to be converging because the force of the inductive bias is most apparent when the learner is confronted with a situation where a straightforward adpositional morphological subcategorization is not possible (i.e., at the stage of morphological reanalysis).

This understanding of the placement typology of infixes necessitates a more constrained view of the Phonology-Morphology interface. Synchronically, morphological objects may target phonological entities in subcategorization. Phonological factors may adjudicate the selection of allomorphs but may never influence the satisfaction of their respective subcategorization restrictions directly. The interaction between phonology and morphol- 
ogy is also indirect at the diachronic level. Changes in morphological subcategorization may be motivated by changes in the phonological system. However, sound change and phonological change do not target morphological processes directly (thus following the exceptionless dictum of the Neogrammarian view of sound change). As the study of the origins of infixes shows, infixes are the results of misanalysis that resulted from ambiguity-inducing changes which originate elsewhere in the system; affixes do not literally move against its underlying nature in response to phonological pressures. It is the ambiguity in the input at the stage of morphological learning that prompts some learners to posit infix-generating subcategorization frames for affixes that were previously adpositional. The asymmetric distribution of infixes is thus the result of a complex interaction between linguistic change and language acquisition, not the results of constraint interaction within the synchronic grammar. The interaction between phonology and morphology is therefore much more limited in scope than is conceived by advocates of OT-Prosodic Morphology. Affix placement, i.e. the linear position of morphemes with respect to other morphological entities, must remain outside the scope of the direct influence of phonological pressures (see Paster (2006) for similar conclusions).

This exercise also brings the discussion of the relations between the studies of the synchronic and diachronic aspects of language into sharper focus. A recurring theme in theoretical discussions of phonology, and elsewhere, centers on the issue of how the formalism proposed is explanatorily adequate (Chomsky 1986). That is, besides arriving at a formalism that describes what happens, many linguists consider it imperative to also restrict the formalism to capture why a phenomenon unfolds only the way it does. In this work, I have argued that the actual locus of explanation resides in the domain of the diachrony and language acquisition (cf. Anderson 1988). Similar views have been made for phonological typology as well, most notably in Juliette Blevins' recent work on Evolutionary Phonology (2004). These authors contend that, while the formal system should model productive grammatical effects, Universal-Grammar-specific explanations should be appealed to only when a phenomenon cannot be accounted for by psychological or historical means. 


\section{Notes}

1. Many thanks to Mary Paster, the audience at the Max Planck Institute of Anthropology at Leipzig, the two anonymous reviewers, and the editors for their discussion and criticism. Any errors are of course my own.

2. I consider an affix infixing if it appears as a segmentally distinct entity between two strings that form a meaningful unit when combined but do not themselves exist as meaningful parts.

3. The database consists of infixation patterns from 112 languages of 26 different phyla and isolates. The guiding principle in compiling the present database is a "the-more-the-merrier" strategy. Languages without infixes were not surveyed, as the main goal of this research is to consider the diversity of infix placement within the set of infixing languages, rather than their geographical distribution.

4. According to van Engelenhoven (2004), the $i$-prefix sometimes nominalizes the verb as an instrument while the $n i$ - prefix nominalizes the verbal act.

5. Kiparsky (1986) uses the term "pivot" to refer to the portion of a stem over which an infix "skips", thus analogous to the operation of negative circumscription (McCarthy and Prince 1990). The notion of pivot adopted here is akin to that of positive circumscription where a pivot describes the circumscribed constituent to which an affix attaches.

6. Languages that do not tolerate the creation of derived discontinuous morphs may respond to failure of satisfying a phonological subcategorization requirement in different ways. Carstairs-McCarthy (1998) identifies three strategies: (a) unsystematic filling of the gaps; (b) systematic morphological filling of the gaps; and (c) systematic syntactic filling of the gaps via periphrasis.

7. For more details on the placement properties of this infix, see Yu (2004).

\section{References}

Albright, Adam C.

2002 The identification of bases in morphological paradigms. Ph.D. diss., Department of Linguistics, University of California, Los Angeles.

Albright, Adam C., and Bruce Hayes

2003 Rules vs. analogy in English past tenses: A computational/experimental study. Cognition 90: 119-161.

Anderson, Stephen

1972 On nasalization in Sundanese. Linguistic Inquiry 3: 253-268.

1988 Morphological change. In Linguistics: The Cambridge Survey, F. Newmeyer (ed.). Cambridge, UK: Cambridge University Press.

Benedict, Paul K.

1943 Secondary infixation in Lepcha. Studies in Linguistics 1 (19). 
Blevins, Juliette

1999 Untangling Leti infixation. Oceanic Linguistics 38 (2): 383-403.

2004 Evolutionary Phonology: The Emergence of Sound Patterns. Cambridge, UK: Cambridge University Press.

Blevins, Juliette, and Andrew Garrett

1998 The origins of consonant-vowel metathesis. Language 74 (3): 508556.

2005 The evolution of metathesis. In The Phonetic Basis of Phonology, B. Hayes, R. Kirchner and D. Steriade (eds.). Cambridge: Cambridge University Press.

Broselow, Ellen, and John McCarthy

1983/1984. A theory of internal reduplication. Linguistic Review 3: 25-88.

Burzio, Luigi

2005 Sources of Paradigm Uniformity. In Paradigms in Phonological Theory, L. J. Downing, T. A. Hall and R. Raffelsiefen (eds.), Oxford: Oxford University Press.

Bybee, Joan

1995 Regular morphology and the lexicon. Language and Cognitive Processes 10 (5): 425-455.

2001 Phonology and Language Use. Cambridge, UK: Cambridge University Press.

Carstairs-McCarthy, Andrew

1998 Phonological constraints on morphological rules. In The Handbook of Morphology, A. Spencer and A. Zwicky (eds.). Oxford, UK: Blackwell Publishers.

Chomsky, Noam

1986 Knowledge of Language. New York: Prager.

Cohn, Abigail C.

1992 The consequences of dissimilation in Sundanese. Phonology 9 (2): 199-220.

Engelenhoven, Aone Thomas Pieter Gerrit van.

2004 Leti: a language of Southwest Maluku. Leiden: KITLV Press.

Flemming, Edward S.

1995 Auditory representations in phonology. Ph.D. diss., Department of Linguistics, University of California, Los Angeles.

Garrett, Andrew

2001 Reduplication and infixation in Yurok: Morphology, semantics, and diachrony. International Journal of American Linguistics 67 (3): 264-312.

Green, Thomas M.

1999 A Lexicographic Study of Ulwa. Ph.D. diss., Department of Linguistics, MIT.

Greenberg, Joseph H. 
1966 Some universals of grammar with particular reference to the order of meaningful elements. In Universals of language, J. H. Greenberg (ed.). Cambridge, Mass.: MIT Press.

1969 Some methods of dynamic comparison in linguistics. In Substance and Structure of Language, J. Puhvel (ed.). Berkeley: University of California Press.

Haas, Mary R.

1977 From auxiliary verb to inflectional suffix. In Mechanisms of Syntactic Change, C. Li (ed.). Austin: University of Texas Press. 525-537.

Haiman, John

1980 Hua: A Papuan Language of the Eastern Highlands of New Guinea. Amsterdam: John Benjamins.

Halle, Morris

2001 Infixation versus onset metathesis in Tagalog, Chamorro, and Toba Batak. In Ken Hale: A Life in Language, M. Kenstowicz (ed.). Cambridge, MA: The MIT Press.

Haspelmath, Martin

1995 The growth of affixes in morphological reanalysis. In Yearbook of Morphology 1994, G. Booij and J. van Marle (eds.). Dordrecht: Kluwer.

Hermans, Ben, and Marc van Oostendorp (eds.)

1999 The Derivational Residue in Phonological Optimality Theory. Amsterdam: John Benjamins.

Inkelas, Sharon

1990 Prosodic Constituency in the Lexicon. New York: Garland Publishing.

Kehoe, Margaret, and Carol Stoel-Gammon

1997 The acquisition of prosodic structure: An investigation of current accounts of chidlren's prosodic development. Language 73 (1): 113144.

Kiparsky, Paul

1986 The phonology of reduplication. Ms. Stanford University.

Martin, Jack B., and Pamela Munro

2005 Proto-Muskogean morphology. In Native Languages of the Southeastern United States, H. K. Hardy and J. Scancarelli (eds.). Lincoln: University of Nebraska Press.

McCarthy, John

1982 Prosodic Structure and Expletive Infixation. Language 58: 574-590.

1999 Sympathy and phonological opacity in Optimality Theory. Phonology 16:331-99.

McCarthy, John, and Alan Prince

1986 Prosodic Morphology. Ms. University of Massachusetts and Brandeis University. 
1990 Foot and word in Prosodic Morphology: the Arabic broken plural. Natural Language and Linguistics Theory 8: 209-283.

1993a Generalized alignment. In Yearbook of Morphology 1993, G. Booij and J. van Marle (eds.). Dordrecht: Kluwer Academics.

1993b Prosodic Morphology I: Constraint interaction and satisfaction. Ms. University of Massachusetts, Amherst, and Rutgers University.

Moravcsik, Edith

1977 On Rules of Infixing. Bloomington: Indiana University Linguistics Club.

2000 Infixation. In Morphology: An International Handbook on Inflection and Word-Formation. Volume 1, G. Booij, C. Lehmann and J. Mugdan (eds.). New York, Berlin: Walter de Gruyter.

Orgun, Cemil Orhan, and Ronald L. Sprouse

1999 From MParse to Control: Deriving ungrammaticality. Phonology 16 191-224.

Paster, Mary

2006 Phonological conditions on affixation. Ph.D. diss., Department of Linguistics, University of California, Berkeley.

Prince, Alan, and Paul Smolensky

1993 Optimality Theory: Constraint interaction in generative grammar Ms. New Brunswick: Rutgers University, Cognitive Science Center.

Shattuck-Hufnagel, Stephanie

1992 The role of word structure in segmental serial ordering. Cognition 42: 213-259.

Smith, Jennifer L.

2004 Making constraints positional: Toward a compositional model of CON. Lingua 114: 1433-1464.

Trubetzkoy, Nikolaj S.

1939 Grundzüge der Phonologie. Prague: Travaux du Cercle linguistique de Prague.

Ultan, Russell

1975 Infixes and their origins. In Linguistic workshop III, H. Seiler (ed.), Munchen: Fink (Structura 9).

$\mathrm{Yu}$, Alan C. L.

2003 The morphology and phonology of infixation. Ph.D. diss., Department of Linguistics, University of California, Berkeley.

2004 Reduplication in English Homeric infixation. In Proceedings of the 34th North East Linguistics Society, K. Moulton and M. Wolf (ed.), Amherst: GLSA.

Zhang, Jie

2001 The effects of duration and sonority on contour tone distributiontypological survey and formal analysis. Ph.D. diss., Department of Linguistics, University of California, Los Angeles. 